\title{
Configurações
}

Revista de sociologia

\section{Maria Beatriz Rocha-Trindade. A Serra e a Cidade - O triângulo dourado do regionalismo. Lisboa: Âncora Editora, 2009}

\section{Esser Jorge Silva}

\section{OpenEdition}

\section{Journals}

\section{Edição electrónica}

URL: http://journals.openedition.org/configuracoes/2190

DOI: 10.4000/configuracoes. 2190

ISSN: 2182-7419

Editora

Centro de Investigação em Ciências Sociais

\section{Edição impressa}

Data de publição: 1 Dezembro 2013

Paginação: $235-240$

ISBN: 1646-5075

ISSN: 1646-5075

\section{Refêrencia eletrónica}

Esser Jorge Silva, « Maria Beatriz Rocha-Trindade. A Serra e a Cidade - 0 triângulo dourado do regionalismo. Lisboa: Âncora Editora, 2009 », Configurações [Online], 12 | 2013, posto online no dia 08 outubro 2014, consultado o 01 maio 2019. URL : http://journals.openedition.org/configuracoes/2190 ; DOI : 10.4000/configuracoes.2190

Este documento foi criado de forma automática no dia 1 Maio 2019.

(c) CICS 


\title{
Maria Beatriz Rocha-Trindade. A Serra e a Cidade - 0 triângulo dourado do regionalismo. Lisboa: Âncora Editora, 2009
}

\author{
Esser Jorge Silva
}

1 Nas encostas da Serra do Açor, no centro de Portugal interiorizado e profundo, dificultado pela natureza agressiva e abandonado pelo Estado, Beatriz Rocha-Trindade descobre os sinais de resistência na preservação do espaço e memória do imaginário social. Num movimento contrário aos fluxos migratórios regionais, a desertificação humana do território não resulta em desmemorização das "gentes da serra" migradas. Levadas para a grande cidade para fugir à pobreza, transportam consigo os marcadores sociais das povoações de origem à espera de um regresso que a passagem do tempo vai negando. Definitivamente fixados nessas longínquas paragens, plantam aí a semente da sua génese, marcando aqui e além os sinais da sua origem.

Uma particularidade apelativa nesta região dirige o olhar para as "[...] muitíssimas casas de construção nova e cuidada que, no entanto, permanecem fechadas durante grande parte do ano" (p. 28) num cenário que mostra muito mais "habitações utilizáveis do que as pessoas efectivamente residentes" (idem). Tal poderia indiciar um "claro contexto de migração", alicerçado "em propósitos de regresso" (idem). Mas esse regresso não se dará; os donos das casas sabem-no. Na realidade essa preservação da possibilidade de regresso configura um dos indicadores de uma "tremenda força aglutinadora das vontades de todas estas populações, designada por Regionalismo" (p. 29).

3 Antes do mais, convém esclarecer uma provável dúvida semântica: Regionalismo não é o mesmo que regionalização ou regiões administrativas. Uma e outra distinguem-se de forma clara: a segunda remete para a questão da organização técnico-administrativa, enquanto a primeira consubstancia um "sentimento que resulta da iniciativa da sociedade civil" (p. 72), responsável pela emergência do Movimento Regionalista, instituto resultante do 
"desfavorecimento sistémico, do isolamento e do esquecimento de que as populações eram vítimas por parte do poder político central" (idem). A compreensão desta força aglutinadora dirige a autora para um aprofundamento temático do triângulo composto pelos concelhos de Arganil, Góis e Pampilhosa da Serra.

O caminho de ferro como investimento estratégico constituiu o momento alto de grande pulsar registado. Até hoje representa "um dos pontos mais visíveis da congregação de vontades catalisada pelo espírito regionalista" (p. 108). Neste caso não teve sucesso; a linha nunca chegou a Arganil, o que teria representado uma inolvidável aproximação da serra à planície. Mas manteve-se a presença de espírito e, sem desistir, reformulada a estratégia, é ao apego e à persistência regionalista, manifesta de variadas formas, que se devem, por exemplo, as estradas nacionais existentes na zona serrana.

Há neste livro uma denúncia do uso da violência legítima sobre a etologia humana; um apelo à preservação de traços culturais que caracterizam o espírito de insubmissão e resiliência, esse estado muitas vezes forjado num caldear de adversidades que "temperou as mentes" (p. 136). Com o decorrer do tempo, as consequências do constrangimento imposto pela aculturação acabam por redundar no aparecimento de uma "típica atitude urbana da cedência ao pessimismo" e de "resignação quanto ao que de mau acontece ou que de bem não está" (p. 138).

6 Sendo um texto que se afirma por ser um estudo etnográfico, revela também uma crítica social às formas como o poder do Estado submete os indivíduos a lógicas que nem sempre são aquelas que a matriz cultural regional definiu para si. O regionalismo enquanto espírito cultural dominante da beira-serra empresta o seu cenário desnivelado e encantador ao olhar descodificador da etnógrafa.

7 Beatriz Rocha-Trindade é uma autora que transporta uma vasta experiência na área das ciências sociais. Pioneira na lecionação da Sociologia das Migrações em Portugal, é uma autora profícua, com uma importante obra dedicada às questões relacionadas com as migrações dispersa por variadas publicações. O livro aqui em análise configura um trabalho iniciado a partir de uma recolha visual obtida nos dois primeiros anos da década de noventa do século XX. Os recursos tecnológicos tornaram-se num auxílio de grande utilidade para a etnógrafa. Neste caso, permitiram-lhe, a partir de um ecrã, sobrevoar a paisagem, captando uma imagem real do seu território de análise.

8 Porém, apesar da facilidade tecnológica, a autora seguiu as práticas de Heródoto e, em junho de 2008 e outubro de 2009, complementa a sua noção territorial experimentando os cheiros da geografia, calcando o solo com os seus pés. Aí encostará os olhos à imagem, confrontando o deslumbre das cores vivas com o manto de negrura, símbolo do luto da paisagem fruto dos incêndios regulares, praticamente anuais. Experimentará o sentimento de orientação dado pela tecnologia, enquanto se perde como um viajante sem destino. Percorrerá estradas hoje acessíveis ao automóvel e ontem apenas acessíveis a pé, mas que nem por isso anularam o sentimento presente de isolamento e de aspiração a uma melhoria das condições: o cenário continua a ser de dificuldades, seja pela obrigação de "andar a pé" (p. 27) e vencer a encosta na realização de um funeral, na ansiedade de um acidente ou de uma doença, num parto difícil ou na demorada chegada de socorro.

9 Os dez anos de trabalho que a autora levou para urdir este livro confirmam a sua familiarização com o objeto, aproximação tão importante quanto o seu contrário - o sempre necessário e indispensável distanciamento. A obra está distribuída por dez capítulos, nos quais a autora lança mão de metodologias de investigação como observação 
direta, pesquisa documental, oralidade, estatísticas oficiais, imprensa local, toponímia e marcos diversos visíveis na região, e os utiliza de forma complementar e transversal para traçar as linhas e as formas interpretativas dos seres humanos. Esta particularidade constitui um exemplo do método etnográfico que constrói a narrativa através de metodologias diversificadas, permanentemente baseadas em recursos do campo. 0 resultado é uma espécie de apelo imagiológico permanente que acompanha o definir do objeto de estudo.

10 Aliás, criar imagens através de palavras é um desafio que se coloca a todos os etnógrafos. Um dos possíveis grandes problemas dos textos de ciências sociais com apelo à natureza, $\mathrm{e}$ cifrados pela morfologia do espaço, reside na dificuldade acrescida com que qualquer autor deparará para meter a terra e a sua textura nos olhos do leitor. Aqui, contudo, não existem apenas imagens extraídas da palavra. O livro é profusamente ilustrado com fotografias de Jorge Barros, recolhidas com o propósito de colorir a cadência da escrita. Quando é a própria obra a convocar um naipe de fotografias para se ilustrar, o risco do efeito de enchimento do olho pela cor é grande. Neste caso, porém, o recurso à imagem fotográfica revela-se harmonioso com a construção escrita. 0 risco de concorrência entre imagem fixada pela lente e imagem fixada pela palavra, que, não raras vezes, se estabelece neste tipo de publicação, é aqui ultrapassado pela complementaridade das duas técnicas. Dois motivos concorrem para o efeito: a captura de fotografias é despida de truques fixando o objeto apenas e esse mesmo objeto é, também ele, o fim conceptual único da carpintaria que a autora usa para construir a sua narrativa.

11 Baseando-se "no pressuposto de que os naturais de uma região onde o emprego escasseia se deslocam para outra, mais ou menos distante, onde consabidamente existe uma significativa oferta de trabalho" (p. 48), a migração interna foi, durante muito tempo, um recurso e uma solução para as situações de pobreza extrema. À partida a migração tem-se por temporária, mas, sempre que a escassez de mão-de-obra persiste, esta dá lugar à migração permanente. Em geral o destino destes fluxos populacionais são, "na sua forma mais típica, as grandes cidades" (p. 47). Para as gentes das serras, a busca de melhores horizontes tem Lisboa como grande "destino a atingir" (idem). Aí ocupam uma série de profissões, desde as de mais fácil abordagem como a agricultura, até as mais elaboradas como a pastelaria, passando pelas emergentes, como a de taxista, ou as mais duras, como a de estivador.

12 Ao fim de certo tempo as povoações da serra acabam representadas em profissões-tipo na grande Lisboa. Alguns exemplos: os engraxadores maioritariamente de Cerdeira (Arganil), os limpa-chaminés, de Fajão (Pampilhosa da Serra), os sapateiros, naturais de Amieiros (freguesia de Alvares, concelho de Góis), os taxistas nascidos em Cortes (freguesia de Alvares em Góis), os sucateiros, provindos de Pessegueiro, Carvoeiro e Coelhal (Pampilhosa da Serra), et cetera.

13 Com o passar dos anos, dá-se um efeito multiplicador migratório. O recrutamento e o desejo manifesto de migrar fazem-se através de canais onde predominam os laços fortes em que "confiança e solidariedade" (p. 48) se constituem em fatores de amparo. Os residentes aceitam a obrigação de orientação e busca de ocupação profissional da primeira instalação. Gradualmente gera-se um efeito comunitário entre conterrâneos e familiares já instalados na capital que orientam os recém-chegados.

14 Esta imposição das circunstâncias e a consequente adesão forçada ao movimento migratório não anularam o que a autora considera uma contradição da mentalidade portuguesa "no que toca à sua ligação afetiva com a terra de nascimento" (p. 47). 
Independentemente da distância, com a partida, não desapegam da origem nem perdem a "intenção e a motivação para regressar" (idem). Por vezes dá-se um corte definitivo, enquanto, "[...] noutras situações, a ligação à terra de origem mantém-se, reforça-se e floresce" (p. 49), sendo este último o caso das "Gentes da Serra" (idem).

Ausentes da sua região de origem, estes deslocados, apesar da assimilação a uma nova realidade regional, mantêm presente as ligações sentimentais de solidariedade, continuando a interessar-se pelo desenvolvimento das suas terras de origem. Vislumbram-se aqui "as características dominantes do chamado 'Espírito Regionalista' das Gentes da Serra, que ainda hoje se mantém" (p. 51).

ção de região aqui vertida, sendo extensiva, tem uma profundidade para além das delimitações geográfica e antropologicamente recortadas, constituindo-se no "suporte de um sentimento de identidade comunitária, de uma consciência colectiva vivenciada por um grupo que sente, reconhece e assume as suas diferenças" (p. 65). Na verdade a realidade regional aqui trazida configura "uma realidade intersubjetiva transportável" (idem) e transcendente que não é redutível às fronteiras físicas, estando incrustadas nos corpos, "pois acompanha as pessoas que a vivenciam para qualquer lugar, independentemente da distância a que ele se encontre" (p. 66).

Uma consciência coletiva muito presente e coesa, mantida e reforçada através de várias ações continuadas, perpetua um espírito que "[se corporiza] através deste grandioso movimento de pessoas e de vontades, em torno do mesmo ideal" (idem), evitando assim a desagregação social que poderia resultar "em virtude da separação e do afastamento mais ou menos forçado" (idem). Esta é a essência do regionalismo, fenómeno social transversal aos concelhos de Arganil, Góis e Pampilhosa da Serra, reconhecido pelos seus habitantes, que, no seu conjunto, entendem estar perante o "Triângulo Dourado do Regionalismo"(p. 28).

Com origem esfumada na memória, o movimento disseminou-se pela generalidade da serra, dando origem a várias instituições imbuídas desse código genético pululado "na extensa e complexa malha associativa descentralizada" (p. 117). Originalmente, os seus dirigentes são personalidades escolhidas não só pelo "seu estatuto social e económico" (idem) mas também pelas "influências que procuram tecer" (p. 118) junto do poder decisor e que lhes permitem concretizar os objetivos. Hoje o movimento regionalista encontra-se em redefinição. $O$ incremento do municipalismo e a existência de orçamento adequado às necessidades populacionais mais prementes libertaram as Ligas de Melhoramentos e as Casas Concelhias de preocupações e assim "ficaram quase esvaziadas de funcionalidade" (p. 127). Os atuais dirigentes, os "filhos do regionalismo", vivem sob o efeito de "algum enfraquecimento" (idem), uma tendência que se verificou por todo o país.

19 Este espírito regionalista depende diretamente da vontade da sociedade civil. A sua subsistência durante os tempos está correlacionada com a existência de necessidades mais básicas. Ultrapassados os tempos de pobreza e grande escassez, os problemas prementes e urgentes parecem ter sido resolvidos. Por outro lado, fruto da continuada desertificação humana, as necessidades locais tornaram-se cada vez menores. Nas associações predominam "as pessoas mais velhas com claro défice das novas gerações" (p. 135). É difícil, segundo a autora, perspetivar o futuro deste movimento. Contudo, caso a mística e o vigor regionalista consigam adequar-se à nova realidade, serão as novas gerações a tomar o lugar. Aí o espírito de missão do regionalismo poderá expressar-se de "diferente forma e usando diferentes caminhos, meios e soluções" (idem). 
regionalismo aqui tratado não consubstancia a noção de bairrismo que, em geral, se traduz num apego exacerbado e não deixa enxergar para além do nariz. Nesta conceção, o regionalismo traduz-se numa espécie de obrigação não forçada a que o indivíduo se submete, com prazer, na busca da realização do bem comum para a sua terra. Trata-se de uma dádiva graciosa, extensível a todos, de cariz benfeitor e contendo propriedades de distinção social imaterializadas, não reivindicadas. Constitui "uma prisão livremente consentida" (p. 69), nos dizeres de Cipriano Barata. Aí manifestam-se elementos centrais, como dar e receber, que Marcel Mauss descortinou em diversas sociedades e que, no limite, resultavam numa aliança na medida em que a capa envolvente do regionalista promove uma relação profunda, alicerçada em atos transversais à totalidade da sociedade serrana.

Como recorda João Alves das Neves, autor do prefácio, é impossível passar por este livro sem nos determos no seu título principal "A Serra e a Cidade". Trata-se de um título que configura a recriação do paralelismo entre realidades paradoxais, aqui fixado pelo inverso ao usado por Eça de Queiroz em A Cidade e as Serras. Nessa obra, a sua personagem principal, Jacinto de Tormes, bem-nascido, educado na mais refinada burguesia, cansado do ócio e da vida mundana, descobre nas suas terras herdadas na serra um lugar ideal para cultivar algum interesse pelo mundo real. A natureza da serra obtém aqui todo o seu esplendor na medida em que é ela que desperta no personagem queirosiano um ímpeto para o trabalho. Tenta desta forma trazer a civilização à serra, num processo em que, para incompreensão da personagem, os residentes e os trabalhadores resistem a essa modernização. Essa resistência levará Tormes a compreender a impossibilidade de rutura cultural e a necessidade de uma aliança entre a tradição e a mudança civilizacional como vetor para a transformação.

Reside aqui o encanto neste jogo de títulos: ao contrário do constatado por Jacinto Tormes, a autora mostra como a mudança humana, da serra para a grande cidade, leva consigo os valores de apego à região e a responsabilidade individual do migrante em manter-se atento às melhorias da terra natal. Aqui, apesar do esforço dos residentes na manutenção das tradições de origem, a cultura regionalista vai, amiúde, perdendo vigor, aguardando as confi gurações de uma nova dinâmica.

\section{AUTHOR}

\section{ESSER JORGE SILVA}

Membro colaborador do Centro de Investigação em Ciências Sociais, Universidade do Minho esser.jorge@gmail.com 